\title{
Editorial
}

\section{Comment on Gas Hydrates}

\author{
J.C. Jones*
}

School of Engineering, University of Aberdeen, UK

One of the rewards of being an Editor-in-Chief is that he or she can read with satisfaction the final published version of papers originally seen as submitted. To have been involved with the refereeing and editing of a paper arguably entitles an Editor-in-Chief to share in a very small degree the sense of pride which the authors themselves experience once a paper is finally in print.

I was in this frame of mind when reading the other day the recent contribution to OTJ by Ohgaki et al. [2]. This is concerned with gas hydrates, and in the relatively short time since its submission to OTJ I have myself undertaken some work on the thermodynamics of natural gas hydrates [2-5]. These are of course gas hydrates with methane as the 'guest molecule'. The authors of [1] emphasise that phase equilibrium exists in the hydrates upon which they perform their measurements. It means that the guest molecules in the hydrates and the same chemical species in gaseous form contacting the hydrate are in phase equilibrium. I have been concerned in my own work with whether under such circumstances the system can be treated as a single component one, in which case the ice has the role of a passive container.

I am aware [5] that ice present in gas hydrates does not have the same thermodynamic properties as ice at the same temperature in the absence of a guest molecule, but those are not the grounds for assigning the ice the role of a component in the thermodynamic sense. A convincing argument for the single component view in relation to natural gas hydrates is that the amount of water vapour in gas in contact with the hydrate will be utterly negligible therefore such gas can be treated as being pure methane.

Readers with comments on this matter are encouraged to send them to the Editor-in-Chief directly. If there are sufficient comments of good quality, a synthesis will be prepared for publication.

\section{REFERENCES}

K. Ohgaki, T. Sugahara, H. Mori, J. Sakamoto, S. Hashimoto, K. Ogata, "Cage occupancy of hydrogen in carbon dioxide, ethane, cyclopropane, and propane hydrates", Open Thermodyn. J., vol. 2, pp. 1-6, January 2008.

[2] J.C. Jones, "Application of the phase rule to natural gas hydrates", Int. J. Mech. Eng. Educ., vol. 36, pp. 182, 2008.

[3] J.C. Jones, "Calculations concerning the phases present in natural gas hydrates", Int. J. Oil Gas Coal Technol., 2009, (in press).

[4] J.C. Jones, "Energy-return-on-energy-invested for natural gas hydrates", Fuel, vol. 88, pp. 1530, 2009.

[5] Jones J.C. Addendum to, “Energy-return-on-energy-invested for natural gas hydrates”, Fuel, vol. 88, pp. 1531, 2009.

(C) J.C. Jones; Licensee Bentham Open.

This is an open access article licensed under the terms of the Creative Commons Attribution Non-Commercial License (http://creativecommons.org/licenses/by-nc/3.0/) which permits unrestricted, non-commercial use, distribution and reproduction in any medium, provided the work is properly cited. 